\title{
O CASO FIAT: ESTUDO DE CASO SOBRE A ESTRATÉGIA DE DESIGN E EXPERIÊNCIA DO USUÁRIO NA INDÚSTRIA AUTOMOTIVA
}

\section{THE FIAT CASE: CASE STUDY ABOUT DESIGN AND USER EXPERIENCE STRATEGY ON THE AUTOMOBILE INDUSTRY}

\author{
Gabriel Santos Garbulho ${ }^{1}$, M.Sc. \\ Adriana Pessoa Barbosa ${ }^{2}$, Bach. \\ (1) Universidade de São Paulo \\ e-mail: gabriel@garbulho.com.br \\ (2) Universidade Federal de Minas Gerais \\ e-mail: adriana.barbosa@altran-consultoria.com.br
}

\begin{abstract}
Palavras-chave em português (em número de três, separadas por vírgulas)
A partir do estudo de caso sobre a consolidação da gestão do design voltada à experiência do usuário no centro de design da Fiat na América Latina, este artigo pretende aprofundar a construção de um entendimento sobre a estratégia de design, e suas relações em âmbito operacional, tático e estratégico de uma grande corporação industrial.
\end{abstract}

Key-words in English (three words, separated by comma)

Starting with the study case about the consolidation of design management focused on the user experience at Fiat Design Center Latin America, this article aims to deepen on the structuration of a understandment about design strategy, and its relations on operational, tactical and strategic level of a large industrial corporation.

\section{Introdução}

A evolução tecnológica das interfaces digitais para uso comum protagoniza uma revolução na disponibilização de serviços envolvendo todos os setores de negócios, e até mesmo as indústrias tradicionais se veem obrigadas a repensar os modelos de negócio convencionais para poder tirar proveito do potencial ainda não totalmente revelado desse cenário de transformação. A indústria automotiva sente os sintomas dessa transformação com a crescente presença de interfaces digitais automotivas, acelerada nos últimos 15 anos, e a mais recente adoção da conectividade do carro com os sistemas de informação das montadoras, que possibilita a viabilização de novas tendências transformadoras como a direção autônoma e a manutenção preditiva (FORBES, 2017).
A construção do diferencial competitivo digital possui direcionamento não só a partir de critérios mercadológicos, mas também com base na capacidade do design de descobrir necessidades emergentes dentro de contextos de uso. Ao viabilizar o acesso a novos mercados a partir da evolução da experiência percebida pelo consumidor final em relação a um produto contando com um modelo mental único, o design passa a ser considerado como uma competência central para as empresas com experiências digitais (MOZOTA, 2011).

O manejo dessa competência se dá com a gestão do design, definida por Gorb (1995) como a "distribuição eficaz, pelos gerentes, dos recursos de design disponíveis à empresa a fim de ajudá-la a atingir seus objetivos", que vem ampliando sua atuação nas esferas estratégicas para apoiar a revisão dos modelos mentais de 


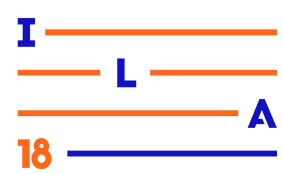

toda a empresa e gerar mais valor agregado (MOZOTA, 2011).

Ao avaliar esse cenário de escalada do design e das áreas de experiência do usuário como influenciadoras da estratégia, Garbulho (2017) fundamentou que "o domínio do pensamento de design permite ao designer ser catalisador da mudança organizacional ao potencializar a integração da equipe de projetos e a formulação de novas ideias a partir de tendências de mercado e da visão do usuário, que geram valor de uso e estão alinhadas à narrativa da estratégia de negócios".

Essa definição resgata a visão de uma evolução natural do design frente aos negócios, envolvido no desenvolvimento de novos produtos para agregar todo o potencial disruptivo e transformador do pensamento de design, ao invés de ser tratado apenas como uma ferramenta para tornar uma ideia mais atrativa (BROWN; KATZ, 2008).

Garbulho (2017) analisa que o pensamento de design se torna vetor de facilitação para a mudança organizacional direcionada pela visão do consumidor. Dado que a estrutura da empresa acompanha a sua estratégia (DRUCKER, 1998), essa orientação implicaria em uma mudança nos processos, mensuração de performance, políticas de recursos humanos e modelos de gestão (GALBRAITH, 2002).

Através de um estudo de caso único, este artigo pretende investigar como se dão as relações entre design e planejamento estratégico que resultam na evolução da estratégia digital de uma empresa industrial, e quais aspectos característicos do segmento automotivo que estão presentes nesses processos.

O objetivo principal deste artigo é poder trazer insumos reais para a discussão acadêmica sobre a evolução da aplicação dos conceitos de design em decisões de negócio, e com isso ampliar o espectro teórico organizado por Garbulho (2017). A investigação também pretende trazer luz à atuação da área de experiência do usuário (user experience ou apenas UX) em relação com outras estruturas produtivas e plataformas, sendo o caso da indústria automotiva um dos mais interessantes e diversos nesse sentido.

A partir desses objetivos principais, foram traçadas perguntas fundamentais que pudessem nortear a estratégia de pesquisa:

(1) Qual o papel da estratégia de design dentro de uma indústria, e como ela modifica o planejamento estratégico?

(2) Como se formula a abordagem de design a partir do direcionamento estratégico definido?

(3) Qual o papel do design digital dentro da visão geral de um produto industrial tradicional?

(4) Como o trabalho e o pensamento de design se tornam direcionadores da estratégia nos âmbitos operacionais e táticos?

\section{Revisão bibliográfica}

A revisão recupera os principais conceitos estruturados por Garbulho (2017) para estabelecer o referencial teórico central sobre a estratégia de design que possa sustentar o estudo de caso proposto no próximo tópico.

O autor levanta que atualmente uma das principais atribuições do designer é transformar a estratégia da empresa, trabalhando dois objetivos principais: a coerência, que diz respeito à relação das aplicações do padrão de design com a estratégia empresarial e seu posicionamento de design; e o próprio padrão de design, que delega sobre a relação do design com fatores críticos de sucesso e sua responsabilidade em relação a outros departamentos da empresa (MOZOTA, 2011). 


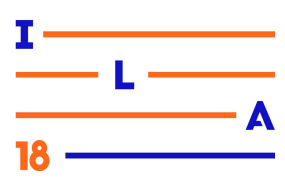

Buchanan (1992) é uma evidência pioneira sobre a evolução do pensamento de design na geração de soluções relacionadas à comunicação, construção, planejamento estratégico ou integração sistêmica, instigando um processo que sintetiza três linhas de raciocínio: as ideias de designers e produtoras sobre seus produtos; a lógica interna de operacionalização dos produtos; e o desejo e habilidade dos seres humanos de usar produtos no dia-a-dia de maneira que reflitam seus valores sociais e pessoais.

\subsection{Sobre a estratégia de design}

Segundo Garbulho (2017), a gestão estratégica de design diz respeito ao desenvolvimento da relação entre design, estratégia e a identidade e cultura da empresa, inserindo o design na formulação estratégica, e determinando a estratégia de design. Estrutura-se uma abordagem sistemática para entender as dinâmicas e efeitos das relações materiais e imateriais que são articuladas através dos artefatos da cultura de design, e as possibilidades de inovação que emergem do design só poderão ser bem aproveitadas se a cultura de design estiver situada com a cultura organizacional, o contexto produtivo e tecnológico, e o contexto de uso, que inclui a sociedade e o mercado (DESERTI; RIZZO, 2014).

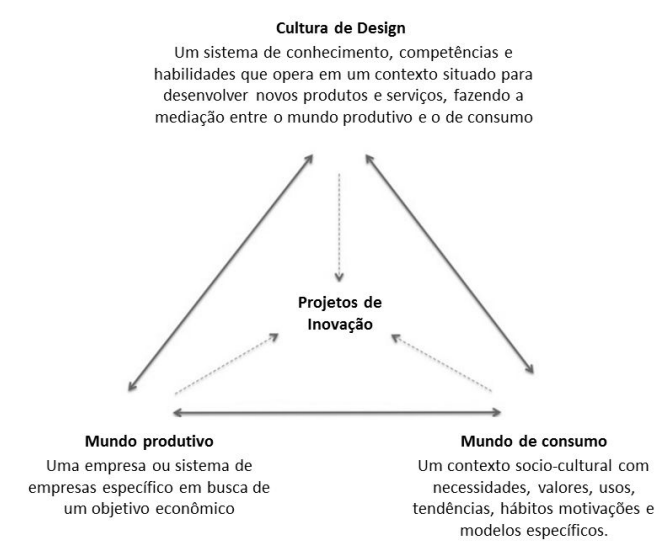

Figura 1-Design Culture, World of production, and world of consumption

Fonte: DESERTI; RIZZO, 2014. Tradução elaborada pelos autores.

A cultura de design é direcionada pelo discurso de design, que consiste na sistematização da pesquisa coletiva para compartilhar significados e linguagens de design, e envolve eventos da área de conhecimento, educadores, artistas, usuários, publicações e os próprios designers, influenciando e modificando modelos socioculturais. Os designers de uma empresa agem como facilitadores do acesso da organização à cultura de design, trazendo seu conhecimento específico para auxiliar a empresa na interpretação e posicionamento dentro do discurso de design (VERGANTI, 2008).

Entre os discursos possíveis, enquanto o design centrado no usuário coloca em evidência a geração de conceitos precedendo o desenvolvimento de produto, a inovação dirigida pelo design recorre a uma etapa ainda mais primária, em que as empresas entendem as dinâmicas dos modelos socioculturais e pensam em novas linguagens e visões de produto em caráter exploratório, conforme a Figura 2 expõe visualmente (VERGANTI, 2008).

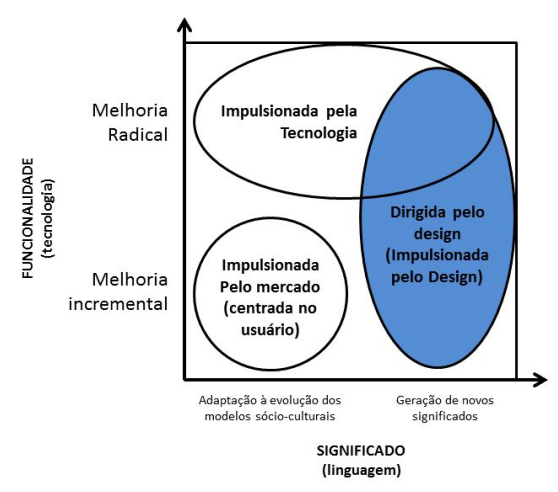

Figura 2 - Functionality (technology) X Meaning (language)

Fonte: VERGANTI, 2008, p.444. Tradução elaborada pelos autores.

A figura traz a interessante perspectiva de que a inovação dirigida pelo design não seria uma resposta direta às necessidades do usuário, mas sim uma proposta de modificação do mercado a 


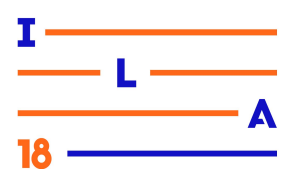

partir da exploração de tendências com grande chance de difusão futura na sociedade. Esse tipo de inovação pode estar associado com disrupções tecnológicas, dado que estas frequentemente causam ou são causadas por mudanças radicais no significado dos produtos (VERGANTI, 2008).

Ampliando a discussão sobre significados estabelecidos pelo design e posicionamento estratégico, Zurlo e Cautela (2014) propõem o uso de narrativas para facilitar a interpretação do processo de criação de sentido para as organizações. Nessa perspectiva, empresas e designers se comportam respectivamente como narrador e leitor, em uma relação na qual o primeiro estabelece o esquemático (frame) de inovação, e o último interpreta, dá a direção, e o materializa (ZURLO; CAUTELA, 2014).

Tomando como eixos os dois principais fatores de direcionamento da narrativa estratégica (mercado e tecnologia), os autores propõem a divisão apresentada na Figura 3, que caracteriza o tipo de narrativa da estratégia de design de acordo com essas premissas (ZURLO; CAUTELA, 2014).

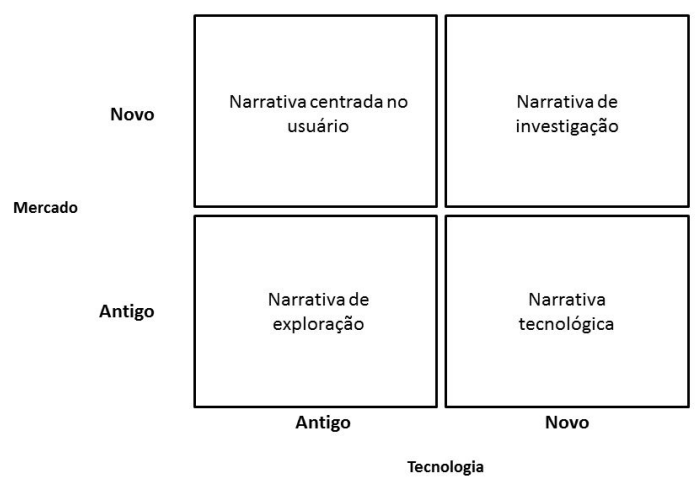

Figura 3 - Market X Technology Fonte: ZURLO; CAUTELA, 2014, p.24. Tradução elaborada pelos autores.

Este modelo propõe quatro narrativas-chave na relação entre inovação de tecnologia e mercado (ZURLO; CAUTELA, 2014), a saber:
- A narrativa de exploração, em que a empresa está direcionada a otimizar os processos de exploração da oferta existente, e não precisa do design de um produto inovador, mas sim da atualização ou complementação do produto atual. Nesse cenário, o design é orientado para o solucionamento de problemas com limitações e oportunidades bem definidas mas sem espaço para expansão do modelo de negócio.

- A narrativa tecnológica, em que o designer é demandado a usar e introduzir uma nova tecnologia para desenvolver um novo produto ou solução. Nesse caso, a liberdade é maior do que a narrativa anterior, embora exista uma estrutura tecnológica predefinida.

- A narrativa centrada no usuário, em que a empresa está ciente da estabilidade tecnológica e demanda ao designer a proposição de um novo cenário e contexto para a expansão do uso da tecnologia, explorado a partir da visão e necessidades dos novos usuários do público pretendido.

- $\quad$ E a narrativa de investigação, em que existe um potencial de inovação maior que das anteriores, pois estas empresas estão à procura de experimentação tecnológica para a criação de novas categorias de mercado, e os designers são demandados a imaginar soluções que possam modificar modelos de negócio existentes ou criar um novo ecossistema de negócios.

O design se funde ao planejamento estratégico ao direcionar as narrativas segundo o campo estratégico que a empresa desenhou, os quais são interpretados pelo designer na figura de conceitos, protótipos e conhecimento visualizável (ZURLO; CAUTELA, 2014).

O verdadeiro propulsor de inovação que pode modificar radicalmente as empresas, seus processos e competências e até mesmo as pessoas da organização está na gestão de 


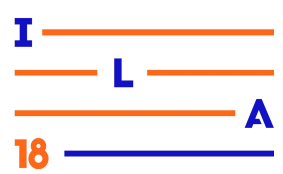

projetos inovadores utilizando uma cultura de design situada na narrativa da empresa.

(DESERTI; RIZZO, 2014)

Ao avaliar o impacto da estratégia de design em empresas brasileiras com atuação digital, Garbulho (2017) concluiu que "a gestão e a cultura de teste e pesquisa em design são as estruturas através das quais se dissemina a atitude de design, aproximando os princípios da estratégia de negócio da entrega de valor para o usuário, ocasionando em mudanças organizacionais que criam ou reforçam diferenciais competitivos".

\section{Estudo de caso}

Para esta investigação, optou-se pela construção de um estudo de caso investigativo que pudesse revelar condições específicas de manejo das estratégias de design dentro da indústria automotiva.

Por ser uma indústria de estruturação complexa devido ao processo industrial em um produto altamente elaborado, cada montadora possui um conjunto de estratégias bastante específico e congruente com suas relações internas.

Tendo em vista o aprofundamento nas especificidades presentes em relações internas, foi elaborado um plano de pesquisa para um estudo de caso único, realizado na Fiat Chrysler Automóveis do Brasil, focado no desenvolvimento dos veículos da marca FIAT que possui maior expressão no mercado nacional em relação às outras marcas de propriedade da holding. Devido à oportunidade da equipe de pesquisa de observar os processos e acessar documentação e estruturas de fórum particular do centro de estilo de Design, este estudo de caso se configura como revelador (YIN, 2015).

Para facilitar o mapeamento dos objetivos e situar o ponto de vista do caso, foi criado um referencial teórico geral sobre a estratégia de design, seguindo a recomendação de YIN
(2015) de concentrar-se na finalidade do trabalho, e trazer à tona os tópicos que serão essenciais para a descrição do caso.

O plano de pesquisa prosseguiu com as seguintes etapas:

$\mathbf{1}^{\mathbf{a}}$ etapa: construção de referencial teórico para a formulação da estratégia de pesquisa.

$2^{\mathbf{a}}$ etapa: levantamento do histórico de projetos relacionados às interfaces do veículo, com atenção especial aos últimos 5 anos.

$3^{\text {a }}$ etapa: elaboração de questionário para investigação de profundidade com os atores do processo relacionado ao desenvolvimento estratégico da área de design.

4 a etapa: execução e tabulação das entrevistas, para posterior análise dos dados.

$5^{\text {a }}$ etapa: consolidação das informações e criação da narrativa dos dados

O caso busca construir uma visão a respeito da recente criação da gerência de UX dentro do Centro de estilo, e como esse fenômeno reflete o posicionamento estratégico do design na empresa.

As entrevistas foram semi-estruturadas e pautadas no questionário descrito na tabela abaixo:

\begin{tabular}{|l|l|}
\hline Conceitos principais & Questões \\
\hline Discurso e cultura de design & $\begin{array}{l}\text { Você consegue traçar as } \\
\text { características principais } \\
\text { posicionamento do design da } \\
\text { empresa? }\end{array}$ \\
\cline { 2 - 2 } & $\begin{array}{l}\text { Como essas características } \\
\text { do posicionamento de design } \\
\text { são transmitidas para o } \\
\text { ambiente de projeto? }\end{array}$ \\
\hline
\end{tabular}


Interaction Latin America

Rio de Janeiro, Brasil - 2018

http://ila.ixda.org/2018

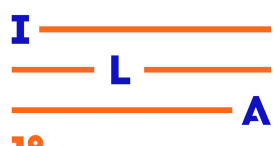

\begin{tabular}{|c|c|}
\hline Narrativa estratégica & $\begin{array}{l}\text { Qual o papel do design nas } \\
\text { decisões estratégicas gerais? } \\
\text { Existe a demanda por } \\
\text { estudos ou avaliações da } \\
\text { área de design para o } \\
\text { patamar de decisões } \\
\text { estratégicas? }\end{array}$ \\
\hline $\begin{array}{l}\text { Disseminação da cultura de } \\
\text { design (teste e pesquisa) }\end{array}$ & $\begin{array}{l}\text { Como as decisões } \\
\text { estratégicas gerais da } \\
\text { empresa transformam a } \\
\text { dinâmica de desenvolvimento } \\
\text { de um projeto? }\end{array}$ \\
\hline \multirow[t]{2}{*}{$\begin{array}{l}\text { Design como competência } \\
\text { central }\end{array}$} & $\begin{array}{l}\text { Você enxerga alguma } \\
\text { característica das interfaces } \\
\text { digitais que seja ou tenha } \\
\text { sido um diferencial } \\
\text { competitivo em algum } \\
\text { momento na linha de } \\
\text { produtos? }\end{array}$ \\
\hline & $\begin{array}{l}\text { Como são definidos os } \\
\text { requisitos de interfaces } \\
\text { digitais do carro? }\end{array}$ \\
\hline Cultura de design & $\begin{array}{l}\text { Como você considera o peso } \\
\text { decisivo das tendências de } \\
\text { mercado no design digital do } \\
\text { carro? E das pesquisas com } \\
\text { o usuário? }\end{array}$ \\
\hline $\begin{array}{l}\text { Design como habilitador da } \\
\text { inovação em modelos de } \\
\text { negócio }\end{array}$ & $\begin{array}{l}\text { Como o cenário de serviços } \\
\text { digitais pode modificar o } \\
\text { modelo de negócio e a } \\
\text { estratégia da indústria como } \\
\text { um todo? }\end{array}$ \\
\hline
\end{tabular}

Tabela 1: Questionário elaborado e conceitos principais para elaboração. Elaborada pelos autores.

Foram entrevistados os três profissionais com participação efetiva e relevante nos fóruns estratégicos da empresa, com destaque ao entrevistado A que possui uma cadeira no conselho da diretoria geral, conforme evidencia tabela abaixo:

\begin{tabular}{|c|c|}
\hline Entrevistado & Cargo \\
\hline A & Diretor de design \\
\hline
\end{tabular}

\begin{tabular}{|c|c|}
\hline B & Gerente de UX \\
\hline C & Líder de pesquisa UX \\
\hline
\end{tabular}

Tabela 2: Lista de Entrevistados e seus respectivos cargos. Elaborada pelos autores.

As entrevistas somam-se a outras evidências, como a observação participativa dos processos operacionais dentro da equipe de UX, e o estudo histórico da evolução das interfaces automotivas, que estará descrito abaixo. Para a análise dos resultados do cruzamento de evidências, foi utilizado o modelo de análise da gestão do design voltada à experiência do usuário proposto por Garbulho (2017), que possibilita uma visualização da estratégia de design em empresas digitais, conforme é possível compreender na figura abaixo:

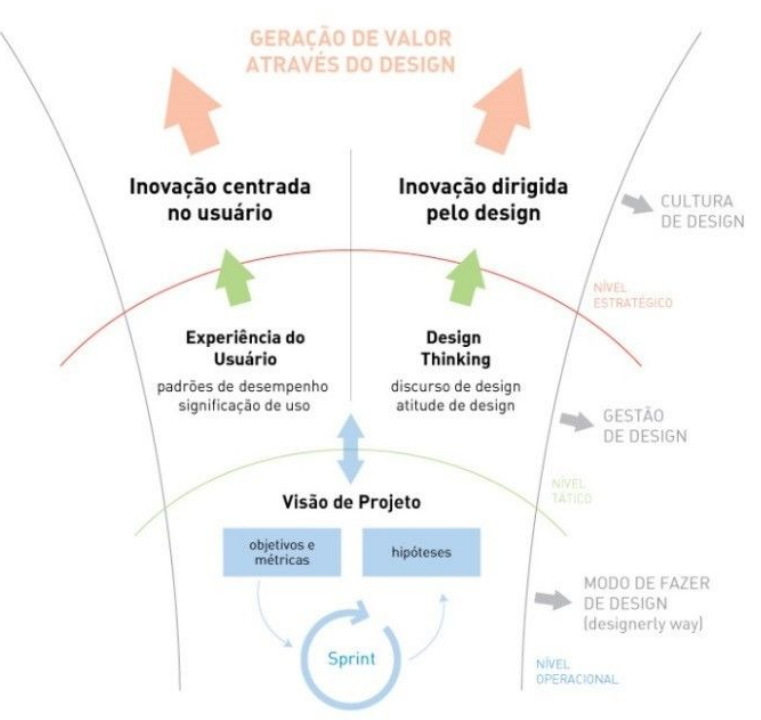

Figura 4: modelo de análise da gestão do design voltada à experiência do usuário (GARBULHO, 2017)

Segundo Garbulho (2017), a figura propõe que a experiência do usuário e o design thinking são os principais operadores para a organização na geração de requisitos do produto, e viabilizam a geração de valor através do design ao propor duas abordagens derivadas da estratégia escolhida: uma mais voltada para UX que fortalece a inovação centrada no usuário e tem sua fundamentação no desenvolvimento do 


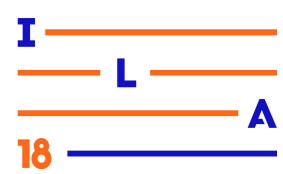

mercado já estabelecido para aquele produto; e a inovação centrada no design, que propõe novos discursos e atitudes de design a partir do uso da reflexão do design junto às unidades de negócio através do design thinking.

A figura sustenta as teses de que a potencialização da cultura de design amplifica a entrega de valor para o usuário, e que a relação entre estratégia e operação pode ser permeável, repensando problemas e avaliando oportunidades que emergem do espaço de projeto.

\section{Resultados}

\subsection{Contexto geral}

A marca Fiat é parte da holding multinacional FCA, e é uma das marcas de automóvel mais tradicionais do Brasil, junto a um grupo de montadoras com mais experiência no mercado brasileiro que inclui Volkswagen, Chevrolet e Ford.

Embora tenha registrado uma redução na participação de mercado em 2017, a empresa ainda mantém o segundo lugar no mercado de veículos leves, e possui três veículos entre os vinte mais vendidos em 2018, segundo levantamento realizado até o mês de junho deste ano (AUTOO, 2018).

Os veículos presentes no top 20 foram projetados no centro de design responsável pelo mercado da FCA na América Latina, localizado na fábrica em Betim / MG. O centro de design vem atuando na adaptação de projetos da marca para o mercado regional desde 2002, e nos últimos dois anos assumiu a responsabilidade pela proposição de projetos destinados à região, ganhando maior atuação estratégica. $O$ centro conta com aproximadamente 140 pessoas trabalhando diretamente nas frentes de design interior, design exterior e UX, sendo um dos maiores centros de design automotivo no Brasil entre todas as montadoras.
As evoluções digitais no uso do veículo, representadas principalmente pelo quadro de instrumentos e a central multimídia, somadas ao novo cenário de serviços conectados ao carro motivaram a organização dessa gerência específica responsável pelos desenvolvimentos e estudos de experiência do usuário.

\subsection{Evolução histórica}

As interfaces dos veículos ganharam implementos tecnológicos na década presente que agregaram novas possibilidades digitais para a interação e os serviços de uso comum do produto. O Fiat Novo Uno, lançado em 2010, é um marco interno desse novo padrão interativo, com a inserção de um display de 3,5" em TFT (Thin-Film Transistor) no quadro de instrumentos, com possibilidade de configuração de função (consumo médio, tempo de viagem) em quatro teclas no volante.

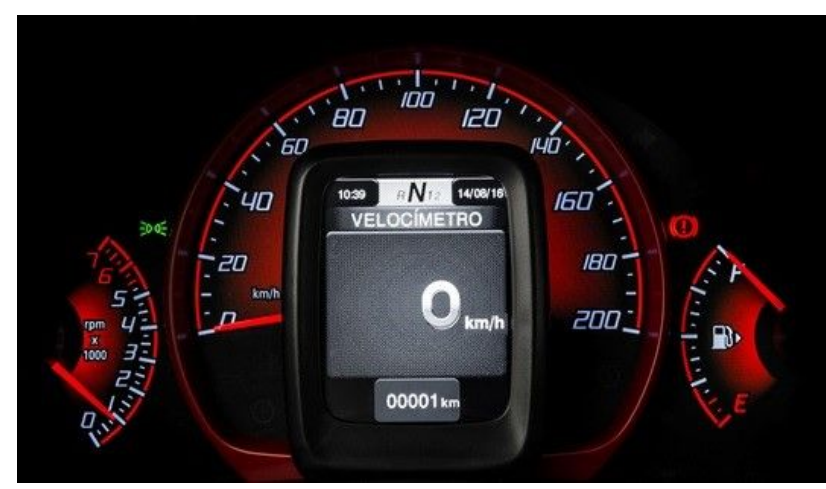

Figura 5: Quadro de instrumentos do Fiat Novo Uno (2010)

Embora os veículos já contassem com displays multimídia desde 2003 com o Fiat Idea, no mesmo ano de 2010 o lançamento do Fiat Bravo traz a navegação por mapa via GPS em uma tela de 6,5", além das funções de celular com o sistema Blue\&Me Nav de conexão bluetooth. 


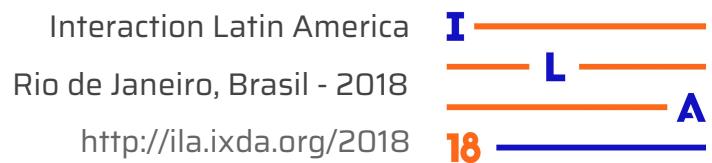

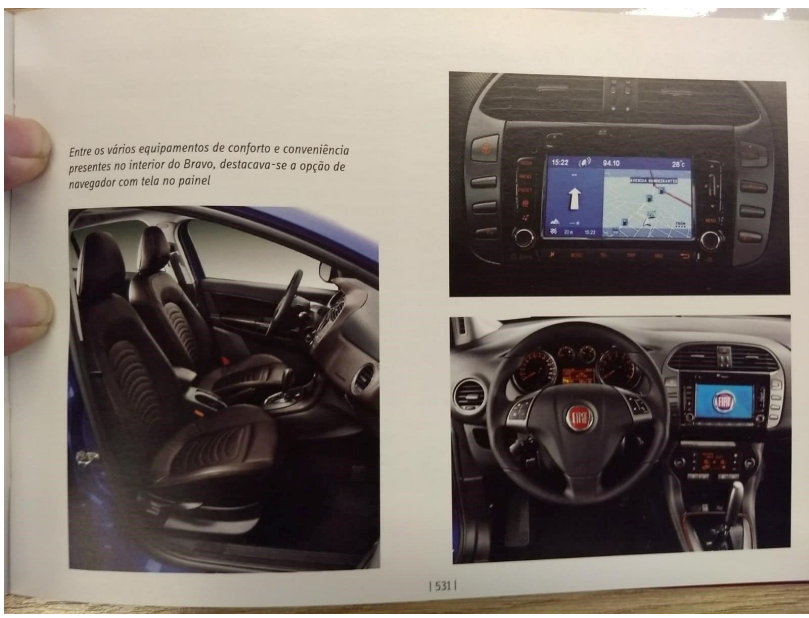

Figura 6: Painel e central multimídia do Fiat Bravo (2010)

A participação das telas digitais no uso do painel do veículo cresce em importância na medida em que o tamanho das telas também amplia as possibilidades de interação.

Da parte do quadro de instrumentos, o Fiat 500 Cabrio Air de 2015 traz o velocímetro digital, além de criar um novo padrão de interface com o uso de elementos gráficos elaborados para auxiliar no acompanhamento dos indicadores do carro em um display colorido.

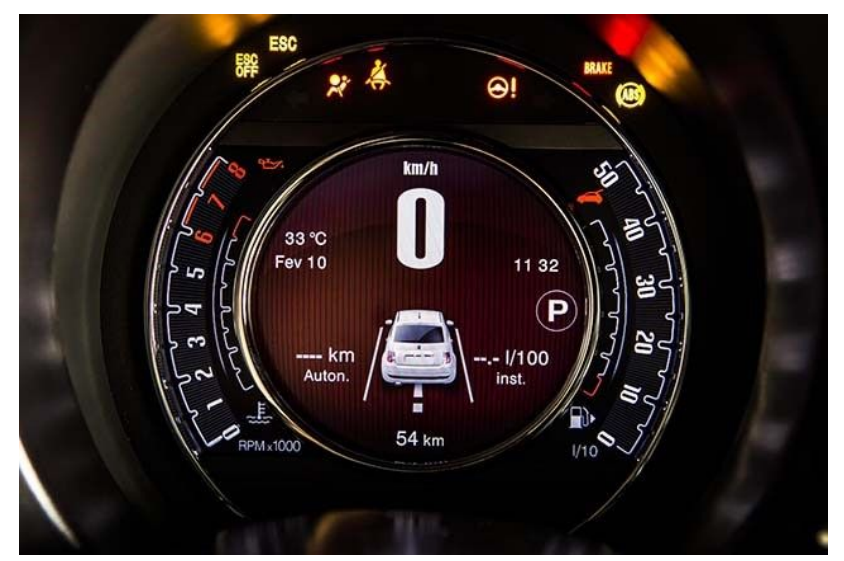

Figura 7: Quadro de instrumentos do Fiat 500L Abarth (2015)

O Fiat Toro de 2016 segue a linha de ampliação das representações digitais, com uma tela de 7" incorporando as funções de navegação, e a função welcome movement em que o veículo realiza uma saudação ao ser ligado pelo usuário.

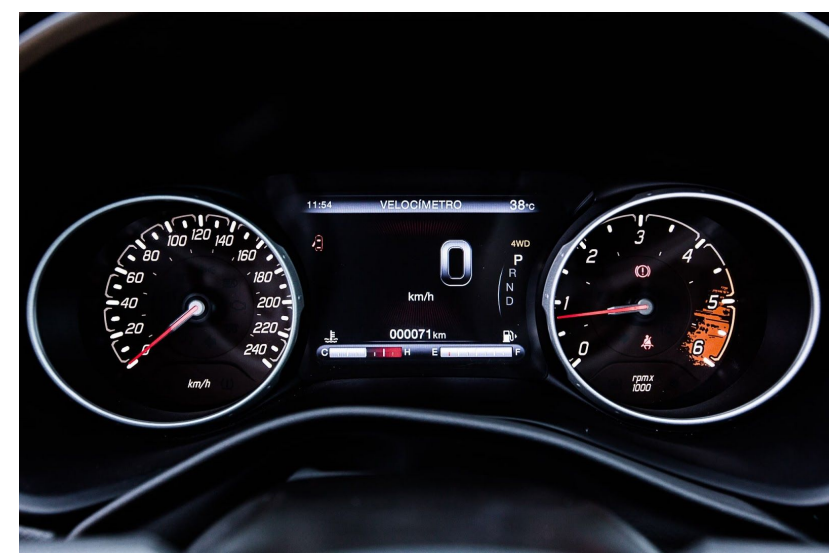

Figura 8: Quadro de instrumentos do Fiat Toro (2016).

Da parte das centrais multimídia, o Fiat Argo de 2017 trouxe uma tela de 7" touchscreen com a integração aos serviços de integração ao smartphone Apple CarPlay e Android Auto, dedicados aos seus respectivos sistemas operacionais, possibilitando o uso de aplicativos adaptados ao contexto de uso do veículo, e aumentando a complexidade de navegação ao possibilitar o uso de aplicativos diversos.

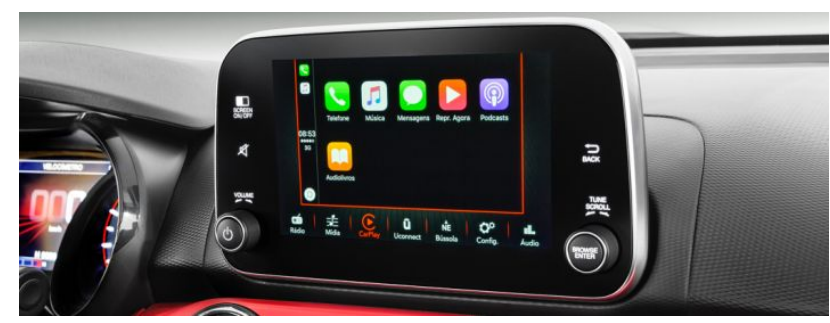

Figura 9: Central multimídia do Fiat Argo (2017)

Em paralelo à evolução das centrais, em 2017 o Live On veio no Mobi Drive para propor uma experiência integrada com o celular, nos moldes do Apple CarPlay e Android Auto, porém utilizando o próprio celular como interface, disponibilizada através de um aplicativo.

Além de disponibilizar o acesso aos aplicativos de mídia dentro dos padrões de segurança e distração do veículo, o aplicativo também conta com uma função chamada Eco Drive, em que o motorista tem acesso a informações do desempenho do carro, fornecidas diretamente pelo sistema eletrônico integrado, através da conexão bluetooth oferecida pela dock (suporte) para o aparelho. 


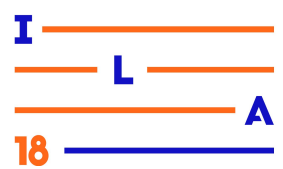

Essas informações de status dos componentes do carro também estão disponíveis em alguns modelos dos painéis de instrumentos.

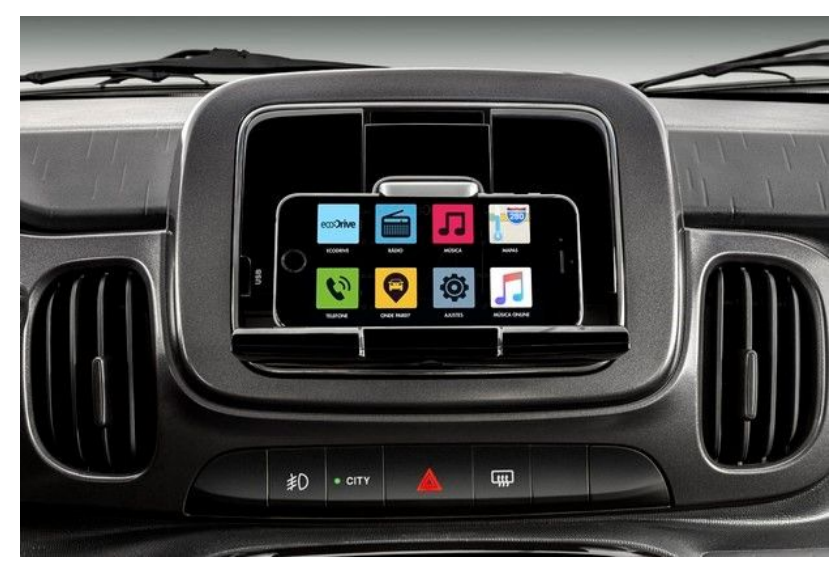

Figura 10: Aplicativo e conexão bluetooth LiveOn (2017)

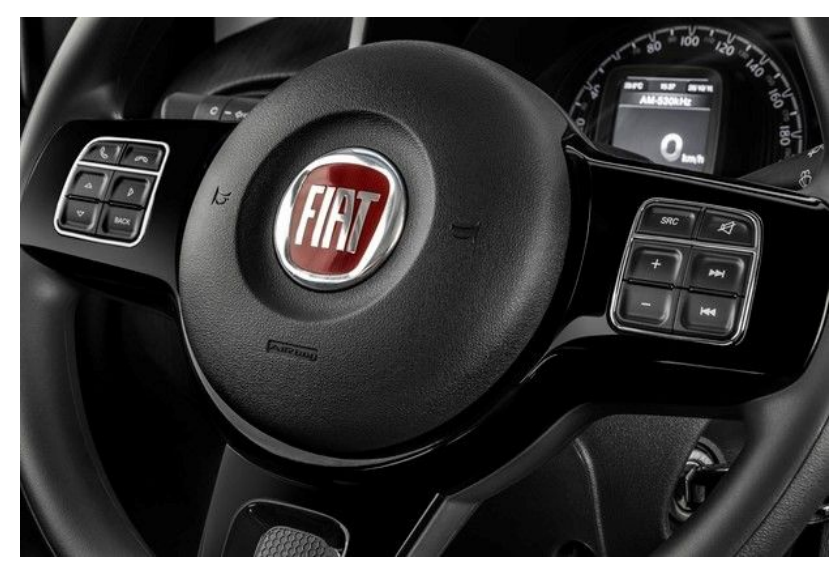

Figura 11: Comandos embutidos no volante do Fiat Mobi Drive (2017)

O momento é de grande importância para a área de UX pois é percebido que as plataformas das interfaces veiculares atingiram um recente estado de maturidade que possibilita repensar tanto a estruturação visual dos elementos básicos, quanto a disponibilização e integração entre serviços. As interações também estão em um ponto de transição, com a incorporação do touchscreen e a sofisticação dos comandos disponíveis no volante. Porém, ainda é preciso investigar as limitações de distração na direção e lidar com um contexto de uso em que a informação imediata é crucial para salvar vidas.

\subsection{Análise das entrevistas}

As entrevistas foram compiladas segundo as respostas das questões elaboradas na escolha metodológica, e as principais respostas nessa sequência foram analisadas para construir uma narrativa de entendimento do papel do design na complexidade organizacional única da FCA. Martins (2004) ressalta que embora haja abertura metodológica para a coleta de dados na pesquisa qualitativa, existe uma preocupação maior nas ciências sociais de fazer os dados falarem da forma mais completa possível, dentro da apreensão e compreensão a realidade. Portanto, a narrativa direta dos dados coletados será apresentada nesse tópico, para ser analisada segundo o modelo de referência no próximo tópico.

Embora já venha desenvolvendo produtos específicos para o mercado brasileiro há mais de 15 anos, o posicionamento do centro de design LATAM passou a ter contornos estratégicos nos últimos 2 anos, ganhando voz nas decisões sobre o portfolio de produtos e realizando estudos para dar mais base às decisões executivas. Esta mudança de posicionamento motivou o crescimento e diversificação de atuação da área, como é o caso do nascimento da gerência de UX.

O entrevistado A pontuou a importância de mostrar à empresa que UX não se trata apenas do desenvolvimento digital e sim da interação do cliente com o produto como um todo, o que demonstra a disposição em integrar a visão da experiência do usuário a todas as fases de desenvolvimento do produto. O entrevistado B pontua que existe um posicionamento específico de UX de trazer informações mais relevantes para o usuário, e deixar claro a maneira como podem ser utilizados os recursos, de maneira que isso possa influenciar inclusive no valor agregado no momento da compra. Entretanto, existe consenso entre os entrevistados que o design exterior ainda cumpre um papel mais forte na estratégia, também por possuir uma estruturação tradicional nas primeiras etapas de decisão. 


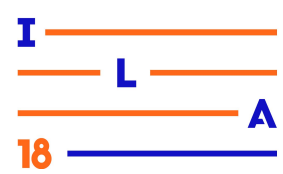

As demandas tem um briefing comercial que é analisado por toda a área, de acordo com as necessidades do projeto e de acordo com a visão da marca. É bastante comum a produção de estudos de design de produto que possam embasar a tomada de decisões executivas. Embora tenha sido ressaltado que o briefing não contempla especificidades de UX, existe uma análise do time de UX para verificar possíveis contribuições. Os entrevistados também pontuaram a importância de um desenvolvimento integrado em que os outros designers também compartilhem das necessidades da área de UX, assim como a integração com os times de engenharia $\mathrm{e}$ qualidade que apontam requisitos importantes de usabilidade e ergonomia a serem incorporados no desenvolvimento.

Além dessas demandas, os entrevistados apontam um segundo caminho experimental em que a área de design realiza pesquisa e propõe produtos que possam apontar para novos diferenciais competitivos, modificando o sentido estratégico do portfolio. A entrevistada $\mathrm{C}$ relata inclusive o crescimento recente das consultas a área de UX para decisões funcionais, e que as análises realizadas pela área já suportaram a tomada de decisões de estratégia em relação à entrega de UX de um produto. $\mathrm{O}$ entrevistado $\mathrm{A}$ ressaltou a área de estudos avançados que realiza propostas que possam agregar tendências e ampliar fronteiras de entrega de valor em todos os aspectos do produto.

O crescimento da participação estratégica da área teve impacto também no modelo de trabalho. $\mathrm{O}$ entrevistado A relata o momento intenso que a área de design vive, com novos demandantes internos e um volume e diversidade de trabalho motivado pelo aumento de know how da área, que pede uma nova dinâmica e atitude de entrega. É importante ressaltar que por ser um produto de manufatura complexa, a produção do carro ainda está atrelada a diversas exigências de entrega das áreas de engenharia. A entrevistada $\mathrm{C}$ relata $\mathrm{a}$ vantagem de que os assuntos de pesquisa que não foram incorporados por falta de prazo no modelo de veículo a ser lançado neste ano podem ser retomados no modelo do próximo ano, devido a periodicidade comercial bastante rígida do segmento. $\mathrm{O}$ entrevistado $\mathrm{B}$ relata que, devido ao longo período que envolve o desenvolvimento de um veículo em qualquer player do mercado, os cenários competitivos oscilam ao longo do próprio desenvolvimento, exigindo invariavelmente mudanças nos rumos de projeto.

Esse cenário favorece portanto uma atuação bastante pragmática e integrada, embora a área esteja traçando caminhos alternativos para poder gerar novos requisitos para os produtos a partir da visão do campo de pesquisa com os usuários. Foi dentro dessa lógica que eles relatam que nasceu o Live ON, que substituiu a central multimídia utilizando o celular para navegação através de conexão bluetooth.

As entrevistas junto à pesquisa do histórico de projetos indicam um esforço por parte da empresa ao longo de cada lançamento em uma visão competitiva de oferecer quadros de instrumentos mais avançados do que os modelos de série do mesmo segmento, e o entrevistado A relata a preocupação em acompanhar a tendência das novas tecnologias, mantendo a facilidade de aprendizado e respeitando as normas de segurança para a ergonomia das interfaces. A entrevistada $\mathrm{C}$ relata a importância de discutir a evolução das normas, dada a mudança recente da capacidade das tecnologias de exposição de dados para os painéis.

Embora o mercado brasileiro tenha fortes tendências a optar pelo veículo de valor mais baixo, o entrevistado A destaca a importância das interfaces multimídia como fator decisivo na compra. Embora as tendências de mercado sejam de grande importância em um mercado tão competitivo como o automotivo, o entrevistado B relata a importância de uma evangelização interna para poder garantir a 


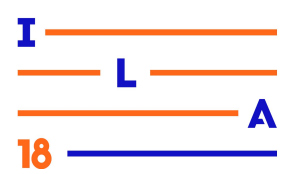

tomada de decisões embasada em pesquisas mais diversas voltadas ao cotidiano de uso do carro, para evitar a reprodução de padrões vistos na indústria automotiva para os quais não há evidência a não ser os dados comerciais. $\mathrm{O}$ entrevistado B pontua que, por haver uma competição de mercado baseada na função aparente (como o tamanho das telas, por exemplo), as tendências podem não necessariamente refletir em inovação, mas em equiparação com a concorrência, o que não ajuda a criar um diferencial competitivo.

Por fim, embora os dados de mercado mostrem uma retomada de vendas da indústria automotiva, os entrevistados enxergam uma mudança progressiva no modelo de negócio, ainda que não exista nenhum cenário próximo que envolva o fim da produção veículos. $\mathrm{Na}$ visão da entrevistada $C$, o carro continua sendo necessário, o modelo de propriedade é que talvez seja revisto. $\mathrm{O}$ entrevistado A aponta para o apoio digital na melhoria do suporte aos serviços físicos, como a manutenção do carro, simplificando rotinas como os bancos fizeram com os aplicativos na última década, por exemplo. $\mathrm{O}$ entrevistado B citou alguns exemplos da indústria, como o Ford Smart Mobility, que demonstram que a mudança de modelo de negócio já é uma realidade trabalhada pelos grandes concorrentes, e o cenário de serviços para o carro será possivelmente mandatório em breve.

\section{Conclusão}

Ao observar a evolução histórica do crescimento do trabalho de UX junto com a evolução das plataformas digitais disponíveis nos painéis automotivos, conseguimos entender a importância contemporânea do caso apresentado, pois o momento de mudança e quebra de paradigmas em relação a atuação do design junto ao desenvolvimento do negócio como um todo é marcante, em especial ao que tange ao design digital.

No caso da FCA é possível enxergar o esforço para equilibrar a competitividade com a necessidade de inovação, presente nas investidas ainda não normatizadas do design na geração inicial de escopo para os produtos. Entretanto, as negociações internas relatadas também nos dão maior clareza a respeito da complexidade que envolve a disrupção em um mercado permeado por diversos rituais comerciais e produtivos. Este caso aponta alguns caminhos que viabilizam inovações, como a integração do trabalho e dos requisitos do design interno, externo e de interfaces, além da participação intensa do design para a tomada de decisões estratégicas, evitando a incongruência do desenvolvimento de um novo produto com as necessidades de usuário e do mercado.

Voltando-se à análise seguindo o modelo de Garbulho (2017), é possível caracterizar no caso estudado uma área voltada à inovação fundamentada em métodos centrados no usuário, com o levantamento de requisitos avaliado estritamente segundo os critérios de uso do mercado planejado. Como levantado na teoria e correspondido no relato do caso, essa estratégia acaba por trazer o foco do design para a melhoria da entrega de valor, mas sem a criação de diferenciais disruptivos, pois a pesquisa está situada em cenários presentes de uso, e portanto lida com o que o usuário já conhece como valor.

Outra característica importante que favorece a geração de valor através do design é a utilização dos aprendizados compilados na visão de projeto para as discussões estratégicas. Quanto mais este aprendizado estiver incorporado no processo da empresa, maior será a capacidade de evolução dentro dos contextos de uso já propostos.

A empresa aponta caminhos interessantes como a alocação de esforços em projetos fora do fluxo do briefing comercial, que podem trazer diferenciais mais radicais desde que a empresa esteja disposta a absorve-los. A integração do design na discussão estratégica já aponta uma visão madura que colabora com esses novos 


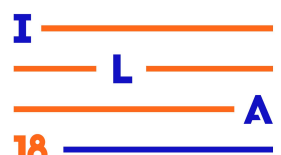

caminhos.

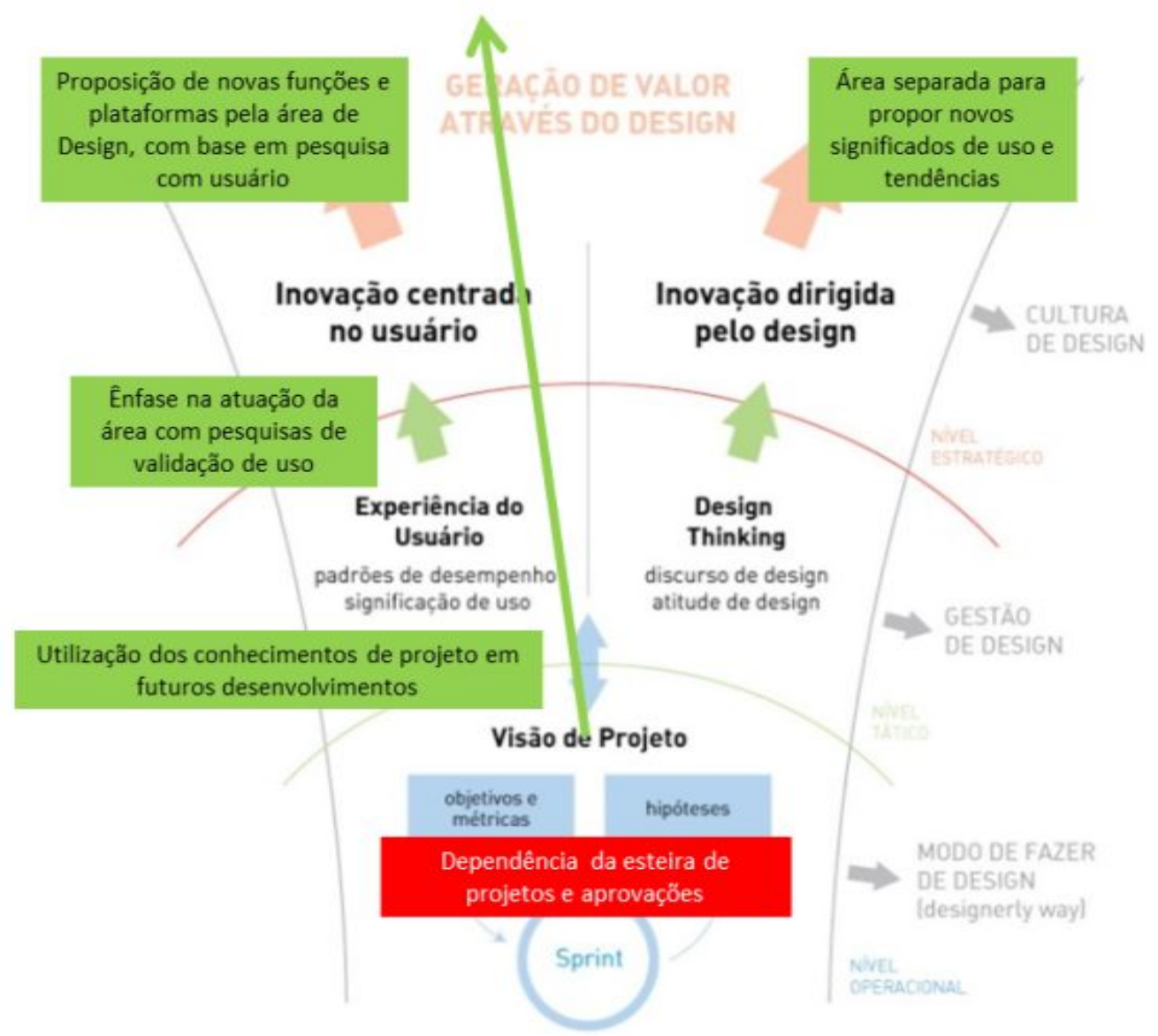

Figura 12: Traçado do posicionamento de design e UX da Fiat, de acordo com o modelo de Garbulho (2017)

A partir da análise do modelo e resgatando os questionamentos iniciais, chega-se à conclusão de que a estratégia de design tem um papel de impulsionar e provocar a inovação na empresa, embora a narrativa principal seja focada na melhoria centrada no usuário, que é mais presente em um desenvolvimento marcado por normatizações de segurança e negociações comerciais complexas.

A abordagem de design vem se modificando para atender a essa recente oportunidade de participar da estratégia, ampliando as execuções de pesquisas de design e workshops de ideação de serviços, e agregando perfis profissionais correlatos para a equipe.

A visão do design digital dentro da visão de produto ainda se restringe ao foco na disponibilização de funções relacionadas ao uso do carro em movimento, mas já é sabido que esse cenário mudará rapidamente com a entrada do carro conectado, aumentando a ênfase em serviços.

O caso traz à tona a importância do pensamento e atuação de design para repensar a entrega de valor do carro, como na ressignificação proposta a partir do ponto de vista da experiência pelo LiveOn para as Centrais Multimídia. Entretanto, esse potencial do design de entregar novas plataformas e experiências ainda está restrito pelo processo produtivo, que é determinante e restritivo neste caso.

Este estudo traz uma colaboração relevante para o entendimento da estratégia de design em 


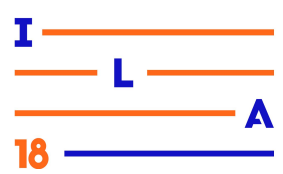

indústrias tradicionais, e pode ser complementado com um estudo de casos múltiplos, ou com uma revisão de cenário futura para traçar as mudanças cronológicas de acordo com novos posicionamentos por parte da mesma empresa.

\section{Referências Bibliográficas}

AUTOO. Carros mais vendidos no Brasil em 2018. Disponível em:

$<$ https://www.autoo.com.br/emplacamentos/vei culos-mais-vendidos/2018/> Acesso em 23/07/2018.

BROWN; KATZ, 2008 Change by Design. Journal of Product Innovation Management , [s.1.], v. 28, n.1, p. 381-383, 2008.

BUCHANAN, R. Wicked Problems in Design Thinking. Design Issues, [s.1.] v. 8, n. 2, pp. 5-21, 1992.

DESERTI, Alessandro; RIZZO, Francesca. Design and the Cultures of Enterprises. Design Issues, [s.1.], v. 30, n. 1, p.36-56, jan. 2014.

DRUCKER, P. Introdução à administração. São Paulo, Pioneira, 1998.

FORBES. Top 6 Digital Transformation Trends in the Automotive Industry. Disponível em:

$<\underline{\text { https://www.forbes.com/sites/danielnewman/2 }}$ 017/07/25/top-6-digital-transformation-trends-i n-automotive/\#44fb4df954e1> Acesso em 21/07/2018.

GALBRAITH, J. Organizing to deliver solutions. Organizational Dynamics, Berlim, v. 31, n. 2, p. 194-207, 2002.

GARBUlHO, G. Avaliando o impacto da estratégia de design em negócios digitais. São Paulo, 2017. 91p. Dissertação (Mestrado) Escola Politécnica da Universidade de São Paulo.
GORB, P. Managing Design in an Uncertain

World. European Management Journal, v. 13, n 1, p.120-127, março 1995.

MARTINS, H. H. Metodologia qualitativa de pesquisa. Educação e Pesquisa, São Paulo, v. 30, n. 2, p.289-300, maio/ago. 2004.

MOZOTA, B.B. Gestão do Design: usando o design para construir valor de marca $\mathrm{e}$ inovação corporativa. Porto Alegre: Bookman, 2011.

VERGANTI, Roberto. Design, Meanings, and Radical Innovation: A Metamodel and a Research Agenda. Journal Of Product Innovation Management, [s.1.], v. 25, n. 5, p.436-456, set. 2008 .

YIN, R. K. Estudo de caso: planejamento e métodos. 5a ed. Porto Alegre: Bookman 2015.

ZURLO, F; CAUTELA, C. Design Strategies in Different Narrative Frames. Design Issues, [s.1.], vol. 30, n. 1, p.19-35, 2014.

\section{Agradecimentos}

Agradecemos à generosidade do Centro de Design da FIAT em abrigar esta pesquisa, às pessoas envolvidas no levantamento e tratamento de informações, e pela disponibilidade e esclarecimento dos profissionais entrevistados. 